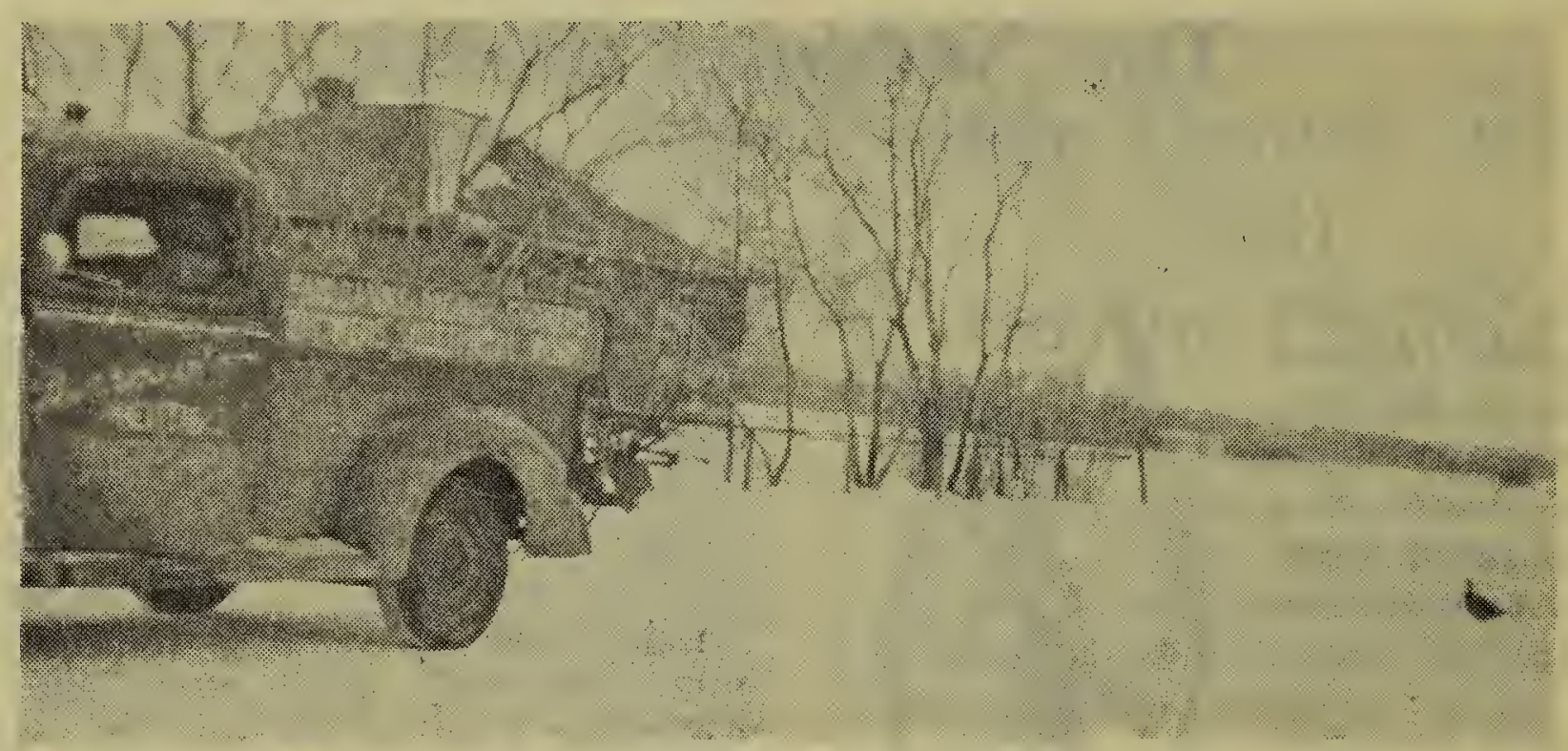

\title{
Melfort's Tame Pheasant
}

By Judge L. T. McKim

In November a wild cock pheasant came into Melfort for the winter. At this day, January 13 , he is still here.

A neighbor of mine, Cam Burroughs has been putting out feed for him and he comes every morning, walks in the gate and has his breakfast. When Mr. Burroughs drives away in his truck the pheasant follows him for a block. After lunch, when Burroughs starts up his tractor, the pheasant flies to it from somewhere in the neighborhood and repeats his performance of the morning.
It is almost certain that he hears the noise of the engine starting as he is nowhere to be seen when the owner comes out to drive to work. Yesterday I drove over and took three snap shots. In order to assist me, Mr. Burroughs bácked up several times and then drove past me. Each time the pheasant ran back with the truck and then followed it when it drove forward.

What an amazing trick for a wild bird to develop!

\section{The "Thing"}

\section{By Frank Baines, Saltcoats}

A dirty white animal about the size of a small skunk was seen here on the Lake road late in the fall. About a week before Christmas it was caught and put in a box, but during the night it escaped. A few day's later it was at Mr. V. Rooke's place, about a quarter of a mile away, but it eluded his efforts to capture it. Later Norman Clause came across it on the road in a very weak condition. He caught it and it was quite docile. He fed it warm new milk and bread and it seemed to feel better.

It is evidently an albino and probably a skunk, though there is very little skunk scent present. Its eyes, nose, lips and upper claws are quite pink. The teeth are cat-like. Something had taken off half its tail and perhaps this injury had caused it to lose control of its scent glands.

It was fed meat and milk and seemed quite contented in an apple-box with a hay bed.

\section{Banded 24 Years Ago}

One of the most amazing and perhaps unequaled records of the life span of Canada Geese has come to light recently. A letter to Judge L. T. McKim, of Melfort, from the Jack Miner Foundation relates that last year they trapped a Can: ada Goose for banding and found that it had been banded by Jack Miner twentyfour years ago. 